\title{
BMJ Open Examining the association between reported COVID-19 symptoms and testing for COVID-19 in Canada: a cross-sectional survey
}

\author{
Roland Pongou, ${ }^{1,2}$ Bright Opoku Ahinkorah (D) , ${ }^{3}$ Marie Christelle Mabeu, ${ }^{4}$ \\ Arunika Agarwal, ${ }^{5}$ Stephanie Maltais (D) , ${ }^{6}$ Sanni Yaya (D) ${ }^{6,7}$
}

To cite: Pongou R,

Ahinkorah B0, Mabeu MC, et al. Examining the association between reported COVID-19 symptoms and testing for COVID-19 in Canada: a crosssectional survey. BMJ Open 2022;12:e056229. doi:10.1136/ bmjopen-2021-056229

- Prepublication history for this paper is available online. To view these files, please visit the journal online (http://dx.doi. org/10.1136/bmjopen-2021 056229).

Received 09 August 2021 Accepted 08 February 2022

Check for updates

(C) Author(s) (or their employer(s)) 2022. Re-use permitted under CC BY-NC. No commercial re-use. See rights and permissions. Published by BMJ.

For numbered affiliations see end of article.

Correspondence to

Professor Sanni Yaya;

sanni.yaya@u0ttawa.ca

\section{ABSTRACT}

Objectives Studies on the management of the COVID-19 pandemic through testing have been conducted in countries that have been hardest hit by this pandemic. Considering the importance of testing in containing the spread of COVID-19, it is useful to have evidence on continuing COVID-19 testing even in countries where the prevalence of COVID-19 is relatively low. We, therefore, examined the association between reported COVID-19 symptoms and testing for COVID-19 in Canada.

Design and settings We conducted an online survey using the SurveyMonkey platform between July and October 2020 across Canada.

Participants A nationally representative sample size of 2790 adult individuals was used.

Results Our findings show that respondents who reported that they and/or members of their households had COVID-19 symptoms were more likely to test for COVID-19 (adjusted OR, aOR 1.91; 95\% $\mathrm{Cl} 1.32$ to 2.76) as compared with those who did not report COVID-19 symptoms. The likelihood of testing for COVID-19 was lower among male respondents compared with females (aOR 0.69; 95\% Cl 0.49 to 0.96 ), respondents aged 65-84 compared with those aged 18-44 (aOR 0.62; 95\% Cl 0.42 to 0.93 ), and respondents in British Columbia compared with those residing in Quebec. Higher odds of testing for COVID-19 were found among respondents who lived in Alberta compared with those who lived in Quebec (aOR 0.42; 95\% $\mathrm{Cl} 0.23$ to 0.75 ) and respondents who had postgraduate education compared with those with high school or less education (aOR 1.84; 95\% $\mathrm{Cl} 1.01$ to 3.36). The association between reported COVID-19 symptoms and testing for COVID-19 was statistically significant among female respondents (aOR 1.52; 95\% $\mathrm{Cl} 1.81$ to 3.52) but not among male respondents.

Conclusions In conclusion, this study provides evidence in support of the hypothesis that there is significant association between reported COVID-19 symptoms and COVID-19 testing among adult Canadians. The study highlights the need for the Canadian government to prioritise subpopulations (ie, males, those aged 65-85, and those with high school or less education) that have lower likelihood of seeking COVID-19 testing to get tested when they have symptoms.
Strengths and limitations of this study

- Our study is among the few studies that have provided an insight into the association between reported COVID-19 symptoms and testing for COVID-19 in Canada.

- Moreover, the sample used for this study is weighted to have a national representation and therefore facilitates the generalisability of the findings to the larger Canadian adult population.

- In terms of limitations, this study was based on a nationally representative data that was collected online, which could have led to sampling bias, as only those with internet access would have been able to access the survey.

- The results cannot be interpreted as causal relationship since the study adopted a cross-sectional design.

\section{INTRODUCTION}

Since the outbreak of the novel coronavirus in November 2019, also known as COVID-19, in Wuhan, China, the disease has spread to 220 countries and territories across the globe. Canada confirmed its first case of COVID-19 on 25 January 2020. ${ }^{1}$ The emergence of the COVID-19 pandemic in Canada has affected all provinces within the country with Ontario and Quebec reporting the highest proportion of infections. ${ }^{23}$ Available statistics show that as of 20 December 2021, Canada had recorded more than 1.9 million cases and over 30000 deaths, with around 1.8 million total recoveries and 64000 active cases. ${ }^{4}$ See figure 1 for the total COVID-19 cases in Canada since the beginning of the pandemic.

COVID-19 is a respiratory infectious disease and is characterised by symptoms that are similar to common cold, Middle East respiratory syndrome and SARS. ${ }^{5}$ Based on the current epidemiological findings, the WHO asserts that the most common symptoms of 


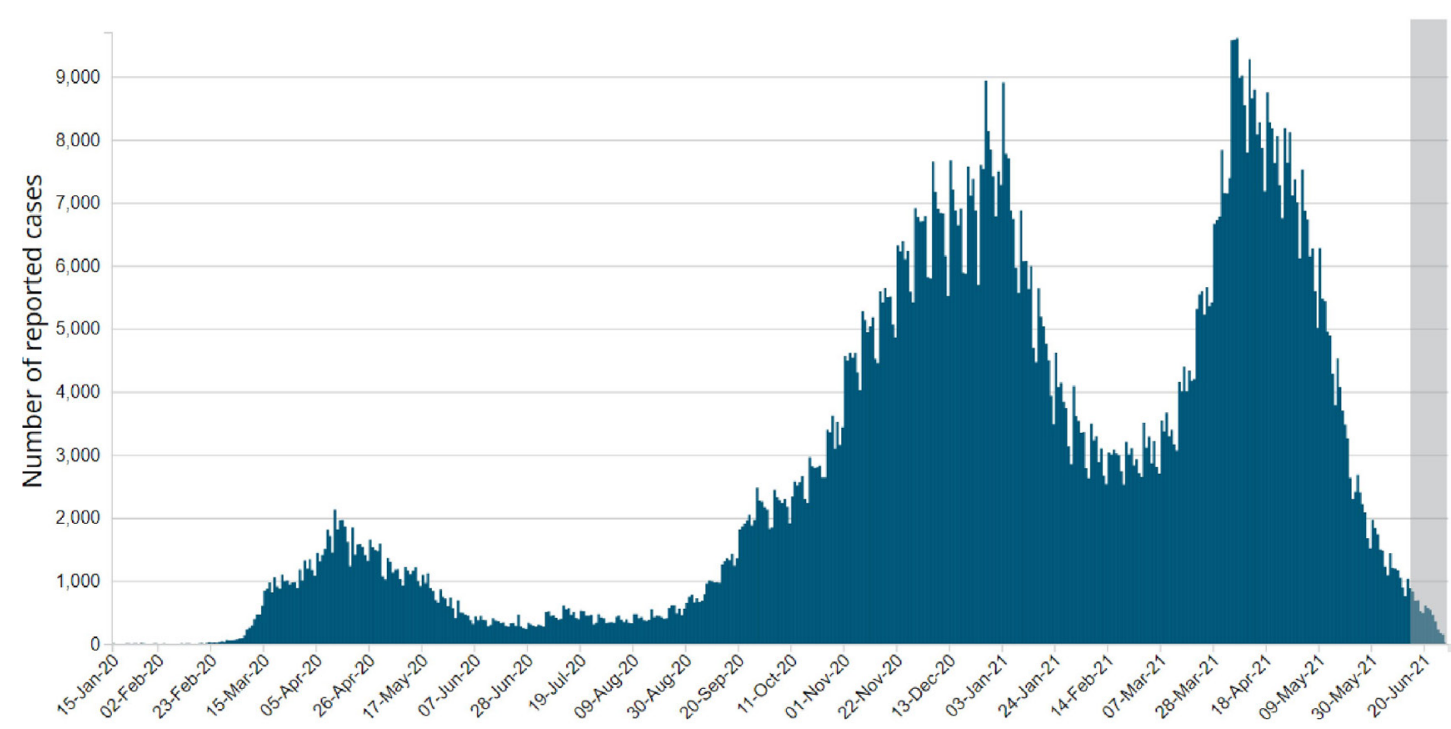

Date of illness onset

Figure 1 COVID-19 cases in Canada since the beginning of the pandemic.

COVID-19 could include runny nose, fever, diarrhoea, dry cough, and tiredness. ${ }^{78}$ However, in severe cases, patients are at risk of developing coagulation disorder, septic shock and dyspnoea. ${ }^{8}$ Nevertheless, some individuals are asymptomatic carriers of the virus and do not show any symptoms. ${ }^{9}$

In Canada, the federal government in collaboration with provincial public health institutions has worked to control the spread of COVID-19 by employing several public health measures such as social (physical) distancing, travel restrictions, closure of schools and increasing testing and tracing capacity. ${ }^{3}$ In this paper, we have focused primarily on the prevalence and determinants of COVID-19 testing in Canada. As of 20 December 2021, the country had about 50635831 tests done for COVID-19 with a test rate of 1324623 per 1 million population. ${ }^{4}$ Irrespective of the type of COVID-19 test used, random testing is postulated to be the most efficient ways of controlling the spread of the disease among the population. ${ }^{10}{ }^{11}$ Yet, Canada's testing capacity has been limited to symptom-based screening. ${ }^{12}$ This situation may have serious repercussion on the country's capacity to effectively control the disease in the wake of yet another wave of COVID-19, hence, warranting the need for a study that examines the association between self-reported symptoms and testing for COVID-19 in Canada.

Despite Canada's relative success in containing the spread of COVID-19, little attention has been paid to assess its COVID-19 testing strategy. Current literature primarily focuses on countries with higher infection and death rates such as Spain, China, UK and USA. ${ }^{13}$ There has been observed heterogeneity in getting tested for COVID-19 among the Canadian adult population that remains sparsely investigated. To fully comprehend the dynamics of COVID-19 tests, we examined the association between reported COVID-19 symptoms and testing for COVID-19. This study is timely to the advancement of effective mechanisms to enhance the effectiveness of COVID-19 testing strategy in Canada. ${ }^{14}$

\section{MATERIALS AND METHODS \\ Study design and data collection}

We conducted an online survey using the SurveyMonkey platform. The portal for this platform is available on the University of Ottawa website in both French and English language (https://socialsciences.uottawa.ca/research/ covid19-survey). This survey has been adapted from Canning et al. ${ }^{15}$ The survey adopted a cross-sectional design, with the data collection taking place in three waves. However, for this study, we relied on data from the first wave which was conducted between July and October 2020 (as shown in figure 1). For data collection, we shared the survey in various social networks and encouraged the snowball method. We also shared the University of Ottawa's Web links via sponsored posts on Facebook in English and French via the university's institutional account. Survey questions were related to sociodemographic characteristics, recent work experience and loss of income, symptoms of COVID-19 among individuals and members of their households, mental health condition, social distancing behaviour and COVID-19 testing. On average, the English survey took $7 \mathrm{~min}$ and French survey took $8 \mathrm{~min}$ to be completed by the respondents. In total, 4875 responses across Canada were collected. Of this number, 3225 responses were in English with the remaining 1650 in French. However, for the purpose of this study only respondents who had complete information on reported COVID-19-related symptoms and that of members of their households were included. Therefore, the sample size used for the analysis is 2790 . 


\section{Patient and public involvement}

Patients and/or the public were not involved in the design, or conduct, or reporting, or dissemination plans of this research.

\section{Outcome variable}

The outcome variable for our analysis was COVID-19 testing. This was derived from the question: 'Have you ever been tested for coronavirus (COVID-19)?' The possible responses to the question were 'yes', 'no' and 'don't know'. For the purpose of this study, missing observations were excluded from the analytical dataset.

\section{Explanatory variables}

The key explanatory variable in this study was COVID-19related symptoms among respondents or a member of their household. There were two explanatory variables that were used to generate this variable: COVID-19-related symptoms among respondents and COVID-19-related symptoms among household members. We derived the former by asking whether the respondents had experienced either fever, dry cough, decreased sense of smell/ taste, other influenza-like symptoms and/or shortness of breath within the past 2 weeks preceding the survey. The responses were 'yes', 'no' and 'don't know'. Respondents who reported having experienced at least one of the aforementioned symptoms were considered as those with reported COVID-19-related symptoms whereas the remaining respondents were categorised as having experienced no COVID-19-related symptoms. For the second explanatory variable, that is, COVID-19-related symptoms among household members, the variable was derived by asking whether 'anyone else in your household besides yourself experienced any of the following symptoms in the past 2 weeks'. The responses were categorised as 'yes', 'no' and 'don't know'. COVID-19-related symptoms among household members were obtained from affirmative responses provided by respondents to at least one of the symptoms among household members (fever, dry cough, decreased sense of smell/taste, other influenza-like symptoms and/or shortness of breath); otherwise, they were categorised as not reporting any COVID-19-related symptoms among household members. Finally, COVID19-related symptoms among respondents or household members was obtained by creating a composite variable from the two variables. Respondents who mentioned that they and/or members of their households had COVID19-related symptoms were put in one category (coded as 1) and those who responded that they and/or members of their households had no COVID-19-related symptoms were put into another category (coded as 0$)$.

\section{Covariates}

We selected nine variables as covariates in this study. These included gender (female and male), age (18-44, 45-64, 65-84 and 85 years and above), province (Quebec, British Columbia, Ontario, Alberta and other provinces), ethnic groups (white, black, mixed race and other-aboriginal/ indigenous, Asian, Latin American, Arab and other ethnicity), being a minority (no and yes), highest level of education (high school or less, college/CEGEP (Collège d'enseignement général et professionnel, known in English as a general and vocational college) or undergraduate university degree, and postgraduate), total personal income in 2019, and number of household members. The number of household members were coded as 1, 2-3 and 4 or more. Total annual income in 2019 was coded as 'less than US\$20 000', 'US\$20 000 to less than US\$50 000 ', 'US $\$ 50000$ to less than US $\$ 100000$ ' and 'US\$100 000 or more'.

\section{Statistical analysis}

Stata V.14 was used to clean the data, recode variables, and analyse the data. Both descriptive (frequencies and percentages $)$ and inferential $\left(\chi^{2}\right.$ test of independence and multivariate logistic regression) analyses were carried out. Frequencies and percentages were first used to describe the socio-demographic characteristics of the respondents and present the proportions of testing for COVID-19 among the respondents using charts. Next, $\chi^{2}$ test of independence was used to show the difference in testing for COVID-19 among the respondents across self-reported COVID-19 symptoms and the sociodemographic characteristics of the respondents. Statistical significance was obtained at $95 \%$ CI. Next, a multivariable logistic regression was employed to examine the effect of reported COVID-19 symptoms on COVID-19 testing among the respondents. Progressive modelling, consisting of gradually controlling for covariates in five regression models, was performed. Model 1 had only reported COVID-19 symptoms and testing. In model 2 , demographic variables such as gender and age were added as controls. In model 3, province, ethnicity and minority group were added to the variables in model 2 as controls. In model 4, education, and total income in 2019 were included in the modelling. In the final model (model 5), number of household members was included to the variables in model 4 . The results were presented as adjusted ORs (aOR) at 95\% CI. Finally, the results of the multivariable logistic regression were disaggregated by gender. Both descriptive statistics and regression results were weighted to have national representativeness. We followed the Strengthening the Reporting of Observational Studies in Epidemiology reporting guideline in reporting the results.

\section{RESULTS}

\section{Sociodemographic characteristics of respondents}

In table 1, we present descriptive weighted statistics on the sociodemographic characteristics of the respondents. Of the 2790 respondents, $51.20 \%$ were females. Majority of the respondents $(44.97 \%)$ were aged 18-44 years. More than one-third of the respondents $(38.45 \%)$ were living in Ontario. Majority of the respondents $(86.08 \%)$ were whites, with approximately $12 \%$ of the total respondents 
Table 1 Descriptive statistics on sociodemographic characteristics of respondents

\begin{tabular}{|c|c|c|}
\hline Variables & $\begin{array}{l}\text { Weighted } \\
\text { frequency }\end{array}$ & $\begin{array}{l}\text { Weighted } \\
\text { percentage }\end{array}$ \\
\hline \multicolumn{3}{|l|}{ Gender } \\
\hline Female & 1428 & 51.20 \\
\hline Male & 1362 & 48.80 \\
\hline \multicolumn{3}{|l|}{ Age } \\
\hline $18-44$ & 1255 & 44.97 \\
\hline $45-64$ & 936 & 33.54 \\
\hline $65-84$ & 550 & 19.71 \\
\hline 85 years and above & 50 & 1.78 \\
\hline \multicolumn{3}{|l|}{ Province } \\
\hline Quebec & 628 & 22.52 \\
\hline British Columbia & 391 & 14.02 \\
\hline Ontario & 1073 & 38.45 \\
\hline Alberta & 320 & 11.47 \\
\hline Other provinces & 378 & 13.54 \\
\hline \multicolumn{3}{|l|}{ Ethnic groups } \\
\hline White & 2402 & 86.08 \\
\hline Black & 85 & 3.06 \\
\hline Mixed race & 126 & 4.52 \\
\hline Other ethnic groups & 177 & 6.35 \\
\hline \multicolumn{3}{|l|}{ Belong to a minority group } \\
\hline No & 2450 & 87.81 \\
\hline Yes & 340 & 12.19 \\
\hline \multicolumn{3}{|l|}{ Highest level of education } \\
\hline High school or less & 384 & 13.75 \\
\hline $\begin{array}{l}\text { College/CEGEP or undergraduate } \\
\text { university degree }\end{array}$ & 1819 & 65.21 \\
\hline Postgraduate & 587 & 21.04 \\
\hline \multicolumn{3}{|l|}{ Total annual income in 2019} \\
\hline Less than US\$20000 & 646 & 23.15 \\
\hline US $\$ 20000$ to less than US\$50 000 & 870 & 31.20 \\
\hline US $\$ 50000$ to less than US $\$ 100000$ & 992 & 35.56 \\
\hline US\$100 000 or more & 281 & 10.08 \\
\hline \multicolumn{3}{|l|}{ No of household members } \\
\hline 1 & 540 & 19.43 \\
\hline $2-3$ & 1616 & 57.91 \\
\hline 4 or more & 635 & 22.76 \\
\hline Total sample size & 2790 & 100.00 \\
\hline
\end{tabular}

CEGEP-General and vocational college; Other ethnic groupsAboriginal/Indigenous, Asian, Latin American, Arab and other ethnicity.

belonging to a minority group. With respect to highest educational attainment, $65.21 \%$ had completed college / / CEGEP or undergraduate university degree. Majority of the respondents had their annual income in the range of US\$50 000 and US\$100 000 for 2019 (35.56\%). Many of the respondents $(57.91 \%)$ belonged to a 2-3-member household while $22.76 \%$ belonged to households with four or more members.

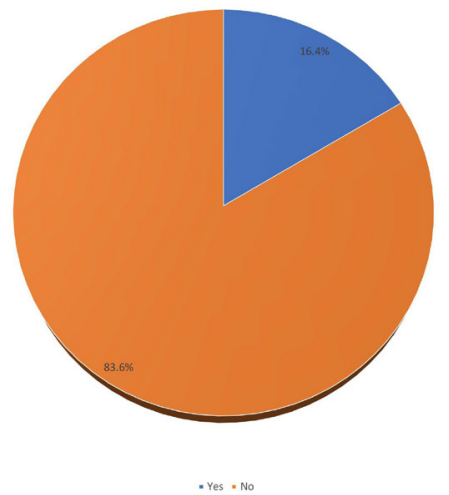

Figure 2 Prevalence of testing for COVID-19 in Canada.

\section{Prevalence of testing for COVID-19}

The results of this study show that, of the entirety of the respondents in this study, $81.8 \%$ had not undergone testing for COVID-19 in Canada even once since the start of the pandemic, with only $18.2 \%$ reporting to have undergone testing for COVID-19 (figure 2).

Testing for COVID-19 by reported COVID-19-related symptoms and across sociodemographic factors of respondents

Testing for COVID-19 had statistically significant difference for COVID-19 symptoms among respondents and/ or household members, gender, age, province and highest level of education. However, total annual income in 2019, minority group, ethnic group and household size were found not to be statistically significant. Across variables that showed statistically significant differences in prevalence of testing for COVID-19, the prevalence of being tested for COVID-19 was almost double among the respondents and/or household members who had experienced COVID-19 symptoms (27.90\%) as compared with those who did not experience COVID-19 symptoms $(16.23 \%)$. As shown in table 2 the highest prevalence of testing for COVID-19 was found among female respondents $(20.71 \%)$, those aged 85 years and above $(25.28 \%)$, respondents who lived in Alberta $(38.85 \%)$ and those with College/CEGEP or undergraduate university degree $(19.13 \%)$.

\section{Multivariable logistic regression results on the association between reported COVID-19 symptoms and testing for COVID-19 disaggregated by gender}

Model 5 of table 3 summarises the multivariable logistic regression results for the association between reported COVID-19 symptoms and testing for COVID-19 while controlling for all covariates. The results showed that respondents who reported that they and/or members of their households had COVID-19 symptoms were more likely to test for COVID-19 (aOR 1.91; 95\% CI 1.32 to 2.76) as compared with those who did not report COVID-19 symptoms. The likelihood of testing for COVID-19 was lower among male respondents compared with females (aOR 0.69; 95\% CI 0.49 to 0.96 ), respondents aged 65-84 
Table 2 Prevalence of testing for COVID-19 across reported COVID-19-related symptoms and sociodemographic factors of respondents

\begin{tabular}{|c|c|c|c|}
\hline Variables & Tested for COVID-19 & $\chi^{2}$ & $P$ value \\
\hline $\begin{array}{l}\text { COVID-19 symptoms among respondents and/or } \\
\text { household member }\end{array}$ & & 59.47 & $<0.001$ \\
\hline No & 16.23 & & \\
\hline Yes & 27.90 & & \\
\hline Gender & & 4.70 & 0.030 \\
\hline Female & 20.71 & & \\
\hline Male & 15.49 & & \\
\hline Age & & 44.54 & $<0.001$ \\
\hline $18-44$ & 21.54 & & \\
\hline $45-64$ & 16.46 & & \\
\hline $65-84$ & 12.73 & & \\
\hline 85 years and above & 25.28 & & \\
\hline Province & & 43.25 & $<0.001$ \\
\hline Quebec & 16.34 & & \\
\hline British Columbia & 7.77 & & \\
\hline Ontario & 18.92 & & \\
\hline Alberta & 38.85 & & \\
\hline Other & 12.32 & & \\
\hline Ethnic groups & & 4.22 & 0.238 \\
\hline White & 17.30 & & \\
\hline Black & 8.46 & & \\
\hline Mixed race & 28.41 & & \\
\hline Other ethnic groups & 27.37 & & \\
\hline Minority group & & 0.42 & 0.515 \\
\hline No & 17.71 & & \\
\hline Yes & 21.47 & & \\
\hline Highest level of education & & 9.05 & 0.011 \\
\hline High school or less & 12.39 & & \\
\hline College/CEGEP or undergraduate university degree & 19.13 & & \\
\hline Postgraduate & 18.95 & & \\
\hline Total income in 2019 & & 5.95 & 0.114 \\
\hline Less than US\$20 000 & 21.85 & & \\
\hline US\$20 000 to less than US\$50 000 & 17.71 & & \\
\hline US $\$ 50000$ to less than US $\$ 100000$ & 16.25 & & \\
\hline US $\$ 100000$ or more & 17.86 & & \\
\hline No of household members & & 1.96 & 0.375 \\
\hline 1 & 19.89 & & \\
\hline $2-3$ & 17.17 & & \\
\hline 4 or more & 19.23 & & \\
\hline
\end{tabular}

compared with those aged 18-44 (aOR 0.62; 95\% CI 0.42 to 0.93 ), and respondents in British Columbia compared with those in Quebec (aOR 0.42; 95\% CI 0.23 to 0.75). Higher odds of testing for COVID-19 were found among respondents who lived in Alberta compared with those who lived in Quebec (aOR 3.11; $95 \%$ CI 1.82 to 5.32) and respondents who had postgraduate education compared with those with high school or less (aOR 1.84; $95 \%$ CI 1.01 to 3.36 ).

The disaggregated results by gender showed that, among male respondents, only province showed statistically significant association with testing for COVID-19. 
Table 3 Multivariable logistic regression results on the association between reported COVID-19 symptoms and testing for COVID-19

\begin{tabular}{|c|c|c|c|c|c|}
\hline Variables & $\begin{array}{l}\text { aOR }(95 \% \mathrm{Cl}) \\
\text { Model } 1\end{array}$ & $\begin{array}{l}\text { aOR }(95 \% \mathrm{Cl}) \\
\text { Model } 2\end{array}$ & $\begin{array}{l}\text { aOR }(95 \% \mathrm{Cl}) \\
\text { Model } 3\end{array}$ & $\begin{array}{l}\text { aOR }(95 \% \mathrm{Cl}) \\
\text { Model } 4\end{array}$ & $\begin{array}{l}\text { aOR }(95 \% \mathrm{Cl}) \\
\text { Model } 5\end{array}$ \\
\hline \multicolumn{6}{|l|}{$\begin{array}{l}\text { COVID-19 symptoms among } \\
\text { respondents and/or household member }\end{array}$} \\
\hline No & Reference & Reference & Reference & Reference & Reference \\
\hline Yes & $2.00^{\star \star \star}$ (1.37 to 2.92$)$ & $1.89^{\star \star \star}(1.29$ to 2.76$)$ & $1.94^{\star \star}$ (1.33 to 2.82$)$ & $1.91^{\star \star}(1.32$ to 2.76$)$ & $1.91^{\star *}$ (1.32 to 2.76$)$ \\
\hline \multicolumn{6}{|l|}{ Gender } \\
\hline Female & & Reference & Reference & Reference & Reference \\
\hline Male & & $0.70^{\star}(0.49$ to 0.98$)$ & $0.67^{*}(0.48$ to 0.93$)$ & $0.71^{\star}(0.50$ to 0.98$)$ & $0.69^{*}(0.49$ to 0.96$)$ \\
\hline \multicolumn{6}{|l|}{ Age } \\
\hline $18-44$ & & Reference & Reference & Reference & Reference \\
\hline $45-64$ & & $0.76(0.54$ to 1.09$)$ & $0.79(0.56$ to 1.13$)$ & $0.87(0.61$ to 1.24$)$ & $0.86(0.60$ to 1.22$)$ \\
\hline $65-84$ & & $0.57^{\star \star}(0.40$ to 0.82$)$ & $0.61(0.42$ to 0.88$)$ & $0.66^{\star}(0.45$ to 0.96$)$ & $0.62^{*}(0.42$ to 0.93$)$ \\
\hline 85 years and above & & $1.27(0.16$ to 10.20$)$ & $1.41(0.15$ to 13.23$)$ & $1.33(0.17$ to 10.35$)$ & $1.10(0.14$ to 8.70$)$ \\
\hline \multicolumn{6}{|l|}{ Province } \\
\hline Quebec & & & Reference & Reference & Reference \\
\hline British Columbia & & & $0.42^{\star \star}(0.24$ to 0.75$)$ & $0.41^{\star \star}(0.23$ to 0.74$)$ & $0.42^{\star \star}(0.23$ to 0.75$)$ \\
\hline Ontario & & & $1.17(0.83$ to 1.66$)$ & $1.17(0.83$ to 1.64$)$ & $1.19(0.85$ to 1.67$)$ \\
\hline Alberta & & & $2.97^{\star \star \star}(1.70$ to 5.18$)$ & $3.08^{\star \star \star}(1.81$ to 5.27$)$ & $\begin{array}{l}3.11^{\star \star \star}(1.82 \text { to } \\
5.32)\end{array}$ \\
\hline Other provinces & & & 0.65 (0.36 to 1.15$)$ & $0.70(0.40$ to 1.21$)$ & $0.72(0.42$ to 1.25$)$ \\
\hline \multicolumn{6}{|l|}{ Ethnic groups } \\
\hline White & & & Reference & Reference & Reference \\
\hline Black & & & $0.38^{\star}(0.14$ to 0.99$)$ & $0.39(0.15$ to 1.03$)$ & 0.38 (0.14 to 1.02$)$ \\
\hline Mixed race & & & $1.46(0.60$ to 3.52$)$ & 1.51 (0.62 to 3.69$)$ & 1.59 (0.75 to 3.36$)$ \\
\hline Other & & & $1.53(0.73$ to 3.21$)$ & 1.61 (0.76 to 3.39$)$ & 1.53 (0.62 to 3.74$)$ \\
\hline \multicolumn{6}{|l|}{ Minority group } \\
\hline No & & & Reference & Reference & Reference \\
\hline Yes & & & 1.03 (0.53 to 1.99$)$ & $0.99(0.51$ to 1.94$)$ & $1.02(0.52$ to 2.01$)$ \\
\hline \multicolumn{6}{|l|}{ Highest level of education } \\
\hline High school or less & & & & Reference & Reference \\
\hline $\begin{array}{l}\text { College/CEGEP or undergraduate } \\
\text { university degree }\end{array}$ & & & & 1.70 (1.00 to 2.89$)$ & 1.68 (0.99 to 2.86$)$ \\
\hline Postgraduate & & & & $1.88^{\star}(1.03$ to 3.44$)$ & $1.84^{*}(1.01$ to 3.36$)$ \\
\hline \multicolumn{6}{|l|}{ Total income in 2019} \\
\hline Less than US\$20 000 & & & & Reference & Reference \\
\hline US\$20 000 to less than US\$50 000 & & & & $0.74(0.48$ to 1.16$)$ & 0.74 (0.48 to 1.15$)$ \\
\hline US\$50 000 to less than US\$100 000 & & & & $0.64(0.41$ to 1.02$)$ & $0.64(0.40$ to 1.02$)$ \\
\hline US\$100 000 or more & & & & $0.68(0.35$ to 1.35$)$ & $0.72(0.37$ to 1.40$)$ \\
\hline \multicolumn{6}{|l|}{ No of household members } \\
\hline 1 & & & & & Reference \\
\hline $2-3$ & & & & & $0.78(0.52$ to 1.17$)$ \\
\hline 4 or more & & & & & 0.74 (0.45 to 1.22$)$ \\
\hline
\end{tabular}

Exponentiated coefficients; $95 \% \mathrm{Cls}$ in brackets.

Model 1: Contains only reported COVID-19 symptoms and testing.

Model 2: Adjusted for gender and age.

Model 3: Adjusted for gender, age, province, ethnicity and minority group.

Model 4: Adjusted for gender, age, province, ethnicity, and minority group, highest level of education and total income in 2019.

Model 5: Adjusted for gender, age, province, ethnicity, and minority group, highest level of education, total income in 2019 and number of household members.

${ }^{*} \mathrm{P}<0.05,{ }^{* \star} \mathrm{p}<0.01,{ }^{\star \star *} \mathrm{p}<0.001$.

aOR, adjusted OR. 
Specifically, the likelihood of testing for COVID-19 was lower among respondents in British Columbia compared with those in Quebec (aOR 0.15; 95\% CI 0.05 to 0.48). Higher odds of testing for COVID-19 were, however, found among respondents who lived in Alberta compared with those who lived in Quebec (aOR 4.12; 95\% CI 1.56 to 10.89) (model 5 of table 4). Among female respondents, reported COVID-19 symptoms, age, province and highest level of education showed statistically significant associations with testing for COVID-19. Specifically, the results showed that female respondents who reported that they and/or members of their households had COVID-19 symptoms were more likely to get tested for COVID-19 (aOR 1.52; 95\% CI 1.81 to 3.52) as compared with those who did not report COVID-19 symptoms. The likelihood of testing for COVID-19 was lower among respondents aged 65-84 compared with those aged 18-44 (aOR $0.34 ; 95 \%$ CI 0.23 to 0.50 ). Higher odds of testing for COVID-19 were found among respondents who lived in Alberta compared with those who lived in Quebec (aOR 2.83; 95\% CI 1.69 to 4.73 ) and respondents who had postgraduate education compared with those with high school or less (aOR 2.05; 95\% CI 1.11 to 3.78) (model 5 of table 5 ).

\section{DISCUSSION}

This study examined the association between reported COVID-19-related symptoms and testing for COVID-19 among the Canadian population. Only $18.2 \%$ of Canadian adults reported that they or a member of their household had been tested for COVID-19. This prevalence is higher than what has been reported in previous nationally representative study conducted in Canada ${ }^{16}$ that found a prevalence of three percent for COVID-19 testing in Canada in January 2020. Although the observed prevalence of COVID-19 testing reflects an improvement in the testing capacity in the country, the prevalence remained low at the time the first wave of our survey was completed. This could be due to the testing guidelines in Canada that is mainly focused on individuals who actively seek a test, thereby resulting in a selective set of cases that are largely presenting symptoms associated with the virus. ${ }^{11}$ The odds of getting tested was significantly associated with report of COVID-19 symptoms at the individual level, with higher education levels, with number of household members and with the province of residence of the respondents.

Respondents who reported that they or members of their households had experienced COVID-19-related symptoms were 2.37 times more likely to get tested as compared with those who did not experience these symptoms. Analogous findings have been reported in studies conducted in Canada. ${ }^{14} 16$ For example, the present analysis is in agreement with Lapointe-Shaw et al ${ }^{14}$ who found COVID-19 testing to be reported in 2\%-9\% of symptomatic responses. The result implies that, despite Canada's relatively effective response to COVID-19 at the federal, provincial and regional levels, there may be several cases that are missed out due to the over-reliance on symptomatic testing, ${ }^{11}$ thus leading to increasing number of COVID-19 cases. Other studies suggest that in situations where COVID-19 testing is most likely to be undertaken by symptomatic individuals, it stifles accurate measurement of COVID-19 infection rate in the larger population. ${ }^{17} 18$ Moreover, persons who do not experience COVID-19related symptoms (asymptomatic) are often reluctant to seek COVID-19 test. ${ }^{19}$ The findings of this study underscore the importance of random testing that the federal, provincial and regional public health departments have not considered to date. The governments should also educate and sensitise the Canadian population about the need to undertake routine testing irrespective of being symptomatic or asymptomatic.

Our findings revealed that the likelihood of testing for COVID-19 was positively associated with higher education level. That is, compared with individuals with high school or less as their highest level of education, those with postgraduate education reported greater odds of testing for COVID-19. The result is incongruent to a related study conducted in Canada ${ }^{16}$ that found no significant association between educational attainment and the possibility of undertaking COVID-19 test. Generally, higher level of education is often associated with enhanced healthcare utilisation, ${ }^{20}$ which could explain higher testing prevalence among respondents with postgraduate or higher educational attainment.

The disaggregated results by gender showed that COVID-19 symptoms had no statistically significant association with testing among males; but for female respondents, this was statistically significant. However, the results indicate that compared with females, males have lower likelihood of testing for COVID-19. Our result mirrors that of a related study from Canada ${ }^{21}$ that showed that males had significantly lower odds of seeking COVID-19 test compared with females. The observed gender differences in COVID-19 testing could be explained by the risk perception and health seeking behaviour of males. ${ }^{21} 22$ In a multicountry study, which included the UK, USA, Australia, Germany, Spain, Italy, Sweden, Mexico, Japan and South Korea, it was revealed that males display significantly lower risk perception about COVID-19 compared with females. ${ }^{23}$ Such low-risk perception tends to adversely affect males' health-seeking behaviour including their uptake of COVID-19 testing, thus making males less likely to go for COVID-19 testing.

The study found significant association between age and COVID-19 testing. Generally, available empirical evidence suggests that older people (65 years and older) are at the greatest risk of COVID-19 infections, ${ }^{24}{ }^{25}$ hence, it is expected that they would be most likely to seek COVID-19 test. Unexpectedly, we found that respondents aged 65-84 years had significantly lower odds of undertaking COVID-19 test compared with those aged 18-44 years. This unexpected result may be attributed to the fact that the current study did not include older 
Table 4 Multivariable logistic regression results on the association between reported COVID-19 symptoms and testing for COVID-19 among male respondents

\begin{tabular}{|c|c|c|c|c|c|}
\hline Variables & $\begin{array}{l}\text { aOR }(95 \% \mathrm{Cl}) \\
\text { Model } 1\end{array}$ & $\begin{array}{l}\text { aOR }(95 \% \mathrm{Cl}) \\
\text { Model } 2\end{array}$ & $\begin{array}{l}\text { aOR }(95 \% \mathrm{Cl}) \\
\text { Model } 3\end{array}$ & $\begin{array}{l}\text { aOR }(95 \% \mathrm{Cl}) \\
\text { Model } 4\end{array}$ & $\begin{array}{l}\text { aOR }(95 \% \mathrm{Cl}) \\
\text { Model } 5\end{array}$ \\
\hline \multicolumn{6}{|c|}{$\begin{array}{l}\text { COVID-19 symptoms among } \\
\text { respondents and/or household } \\
\text { member }\end{array}$} \\
\hline No & Reference & Reference & Reference & Reference & Reference \\
\hline Yes & 1.40 (0.64 to 3.09$)$ & 1.37 (0.61 to 3.08 ) & 1.33 (0.58 to 3.08 ) & 1.32 (0.58 to 2.99$)$ & 1.31 (0.57 to 2.97$)$ \\
\hline $18-44$ & & Reference & Reference & Reference & Reference \\
\hline $45-64$ & & 0.85 (0.42 to 1.75$)$ & 0.88 (0.43 to 1.80$)$ & 1.05 (0.51 to 2.15$)$ & 1.05 (0.51 to 2.13 ) \\
\hline $65-84$ & & 0.99 (0.50 to 1.97$)$ & 1.07 (0.53 to 2.16$)$ & 1.20 (0.59 to 2.43$)$ & 1.16 (0.57 to 2.37$)$ \\
\hline 85 years and above & & - & - & - & - \\
\hline \multicolumn{6}{|l|}{ Province } \\
\hline Alberta & & & $3.82^{\star *}(1.46$ to 10.02$)$ & $4.08^{\star *}(1.55$ to 10.75$)$ & $4.12^{\star \star \star}(1.56$ to 10.89$)$ \\
\hline Other provinces & & & 0.49 (0.14 to 1.66$)$ & 0.51 (0.15 to 1.72$)$ & 0.53 (0.16 to 1.80$)$ \\
\hline \multicolumn{6}{|l|}{ Ethnic groups } \\
\hline White & & & Reference & Reference & Reference \\
\hline Black & & & 0.18 (0.03 to 1.12$)$ & 0.23 (0.04 to 1.42$)$ & 0.23 (0.04 to 1.47$)$ \\
\hline Mixed race & & & 1.35 (0.35 to 5.29$)$ & 1.54 (0.40 to 5.96$)$ & 1.61 (0.40 to 6.40$)$ \\
\hline Other & & & 1.73 (0.54 to 5.49$)$ & $1.88(0.60$ to 5.90$)$ & 1.90 (0.61 to 5.97$)$ \\
\hline \multicolumn{6}{|l|}{ Minority group } \\
\hline No & & & Reference & Reference & Reference \\
\hline \multicolumn{6}{|l|}{ Total income in 2019} \\
\hline Less than US\$20000 & & & & Reference & Reference \\
\hline $\begin{array}{l}\text { US } \$ 20000 \text { to less than } \\
\text { US } \$ 50000\end{array}$ & & & & 0.63 (0.28 to 1.43$)$ & 0.63 (0.27 to 1.44$)$ \\
\hline $\begin{array}{l}\text { US } \$ 50000 \text { to less than } \\
\text { US } \$ 100000\end{array}$ & & & & 0.56 (0.23 to 1.32$)$ & 0.55 (0.23 to 1.30$)$ \\
\hline US\$100 000 or more & & & & $0.45(0.13$ to 1.51$)$ & 0.49 (0.15 to 1.60$)$ \\
\hline \multicolumn{6}{|l|}{ No of household members } \\
\hline 1 & & & & & Reference \\
\hline $2-3$ & & & & & 0.72 (0.35 to 1.45$)$ \\
\hline 4 or more & & & & & 0.64 (0.24 to 1.68$)$ \\
\hline
\end{tabular}

Exponentiated coefficients; 95\% Cls in brackets.

Model 1: Contains only reported COVID-19 symptoms and testing.

Model 2: Adjusted for gender and age.

Model 3: Adjusted for gender, age, province, ethnicity and minority group.

Model 4: Adjusted for gender, age, province, ethnicity, and minority group, highest level of education and total income in 2019.

Model 5: Adjusted for gender, age, province, ethnicity and minority group, highest level of education, total income in 2019 and number of household members.

${ }^{*} \mathrm{P}<0.05,{ }^{\star *} \mathrm{p}<0.01,{ }^{* \star *} \mathrm{p}<0.001$

aOR, adjusted OR. 
Table 5 Multivariable logistic regression results on the association between reported COVID-19 symptoms and testing for COVID-19 among female respondents

\begin{tabular}{|c|c|c|c|c|c|}
\hline Variables & $\begin{array}{l}\text { aOR }(95 \% \mathrm{Cl}) \\
\text { Model } 1\end{array}$ & $\begin{array}{l}\text { aOR }(95 \% \mathrm{Cl}) \\
\text { Model } 2\end{array}$ & $\begin{array}{l}\text { aOR }(95 \% \mathrm{Cl}) \\
\text { Model } 3\end{array}$ & $\begin{array}{l}\text { aOR }(95 \% \mathrm{Cl}) \\
\text { Model } 4\end{array}$ & $\begin{array}{l}\text { aOR }(95 \% \mathrm{Cl}) \\
\text { Model } 5\end{array}$ \\
\hline \multicolumn{6}{|l|}{$\begin{array}{l}\text { COVID-19 symptoms } \\
\text { among respondents and/ } \\
\text { or household member }\end{array}$} \\
\hline No & Reference & Reference & Reference & Reference & Reference \\
\hline Yes & $2.63^{\star \star \star}(1.87$ to 3.70$)$ & $2.50^{\star \star \star}(1.79$ to 3.48$)$ & $2.60^{\star \star *}(1.88$ to 3.60$)$ & $2.49^{\star \star \star}(1.79$ to 3.48$)$ & $1.52^{\star \star \star}$ ( 1.81 to 3.52$)$ \\
\hline $18-44$ & & Reference & Reference & Reference & Reference \\
\hline $45-64$ & & $0.70^{*}(0.51$ to 0.95$)$ & $0.72^{*}(0.53$ to 0.98$)$ & 0.77 (0.55 to 1.06$)$ & 0.74 (0.53 to 1.03$)$ \\
\hline $65-84$ & & $0.34^{* * *}(0.24$ to 0.47$)$ & $0.35^{\star \star *}(0.25$ to 0.50$)$ & $0.37^{\star \star \star}(0.26$ to 0.53$)$ & $0.34^{\star \star \star}(0.23$ to 0.50$)$ \\
\hline 85 years and above & & $1.42(0.17$ to 11.97$)$ & 1.59 (0.18 to 14.31$)$ & 1.44 (0.19 to 10.79$)$ & 1.20 (0.16 to 8.92$)$ \\
\hline \multicolumn{6}{|l|}{ Province } \\
\hline Alberta & & & $2.65^{\star \star \star}(1.53$ to 4.57$)$ & $2.79^{\star \star \star}$ (1.67 to 4.67$)$ & $2.83^{\star \star \star}(1.69$ to 4.73$)$ \\
\hline Other provinces & & & 0.81 (0.44 to 1.49$)$ & 0.89 (0.51 to 1.55$)$ & 0.91 (0.53 to 1.58$)$ \\
\hline \multicolumn{6}{|l|}{ Ethnic groups } \\
\hline White & & & Reference & Reference & Reference \\
\hline Black & & & 0.64 (0.23 to 1.82$)$ & 0.59 (0.21 to 1.69$)$ & 0.57 (0.20 to 1.64$)$ \\
\hline Mixed race & & & 1.74 (0.76 to 4.00$)$ & 1.70 (0.73 to 3.97$)$ & 1.68 (0.51 to 2.22$)$ \\
\hline Other & & & 1.11 (0.55 to 2.26$)$ & 1.08 (0.52 to 2.46$)$ & 1.07 (0.72 to 3.92$)$ \\
\hline \multicolumn{6}{|l|}{ Minority group } \\
\hline No & & & Reference & Reference & Reference \\
\hline \multicolumn{6}{|l|}{ Highest level of education } \\
\hline \multicolumn{6}{|l|}{ Total income in 2019} \\
\hline Less than US\$20000 & & & & Reference & Reference \\
\hline $\begin{array}{l}\text { US } \$ 20000 \text { to less than } \\
\text { US } \$ 50000\end{array}$ & & & & 0.85 (0.53 to 1.37$)$ & 0.84 (0.48 to 1.15$)$ \\
\hline $\begin{array}{l}\text { US } \$ 50000 \text { to less than } \\
\text { US } \$ 100000\end{array}$ & & & & 0.72 (0.44 to 1.15$)$ & 0.73 (0.40 to 1.02$)$ \\
\hline US\$100 000 or more & & & & 0.87 (0.47 to 1.63$)$ & 0.91 (0.48 to 1.68$)$ \\
\hline \multicolumn{6}{|l|}{ No of household members } \\
\hline 1 & & & & & Reference \\
\hline $2-3$ & & & & & 0.82 (0.56 to 1.19$)$ \\
\hline 4 or more & & & & & 0.73 (0.47 to 1.14$)$ \\
\hline
\end{tabular}

Exponentiated coefficients; 95\% Cls in brackets.

Model 1: Contains only reported COVID-19 symptoms and testing.

Model 2: Adjusted for gender and age.

Model 3: Adjusted for gender, age, province, ethnicity and minority group.

Model 4: Adjusted for gender, age, province, ethnicity and minority group, highest level of education, and total income in 2019.

Model 5: Adjusted for gender, age, province, ethnicity and minority group, highest level of education, total income in 2019 and number of household members.

${ }^{*} \mathrm{P}<0.05,{ }^{\star *} \mathrm{p}<0.01,{ }^{* \star *} \mathrm{p}<0.001$

aOR, adjusted OR. 
people living in long term care homes, nursing homes or retirement homes. Report from the 2016 census shows that $6.8 \%$ of Canadians aged 65 years and older were residing in nursing homes or senior residences; however, this proportion increases to $30 \%$ when only those aged 85 years and older are considered. ${ }^{26}$ This inherent limitation of our study explains the observed lower likelihood of COVID-19 testing among those aged 65-84 years.

Lower odds of testing were found among respondents in British Columbia compared with those in Quebec. Also, respondents who lived in Alberta had greater likelihood of undergoing COVID-19 test compared with those who resided in Quebec. This observation could be linked to the administrative, management and governance disparities. For instance, Alami et al $l^{27}$ posit that unlike Quebec where substantial governance challenges concerning the clarification of roles and alignment of positions between the provincial government and large municipalities exist, ${ }^{27}$ Alberta experienced stronger governance coherence and response to the pandemic, translating to greater odds of testing for COVID-19 in Alberta compared with Quebec.

\section{Strengths and limitations}

Our study is among the few studies that have provided an insight into the association between reported COVID-19 symptoms and testing for COVID-19 in Canada. Moreover, the sample used for this study is nationally representative and therefore facilitates the generalisability of the findings to the larger Canadian population. In terms of limitations, this study was based on a nationally representative data that was collected online, which could have led to sampling bias, as only those with internet access would have been able to access the survey. Due to the nationally representativeness of the data, we can generalise the findings to the larger Canadian adult population. However, several associations cannot be interpreted as causal relationship since the study adopted a cross-sectional design. Perhaps, a longitudinal study would be helpful in ascertaining and establishing a causal relationship between the reported COVID-19 symptoms and COVID-19 testing among the Canadian population. Again, data collection was conducted online. Hence, due to the lack of verification, the accuracy of reporting could be a limitation. Finally, there were no results on testing and the rate of asymptomatic cases in this paper to strengthen the related conclusion.

\section{CONCLUSIONS}

In conclusion, this study provides evidence in support of the hypothesis that there is significant association between reported COVID-19 symptoms and COVID-19 testing among the adult Canadian population. The study highlights the need for the Canadian government to prioritise subpopulations (ie, males, those aged 65-85, and those with high school or less education) that have lower likelihood of seeking COVID-19 testing. Also, to accelerate
COVID-19 testing in Canada, it will be important for the capacity of provinces, especially British Columbia and Quebec, to be strengthened and expanded to accommodate the population's need for COVID-19 tests.

\section{Author affiliations}

${ }^{1}$ Department of Economics, University of Ottawa, Ottawa, Ontario, Canada

${ }^{2}$ Center for African Studies, Harvard University, Cambridge, MA, USA

${ }^{3}$ University of Technology Sydney, Sydney, New South Wales, Australia

${ }^{4}$ Department of Economics, Stanford University, Stanford, California, USA

${ }^{5}$ Department of Global Health and Population, Harvard T.H. Chan School of Public Health, Boston, Massachusetts, USA

${ }^{6}$ School of International Development and Global Studies, University of Ottawa, Ottawa, Ontario, Canada

${ }^{7}$ The George Institute for Global Health, Imperial College London, London, UK

Acknowledgements We thank Policy Horizons Canada for supporting our research. We also acknowledge generous research support from the SSHRC's Partnership Engage Grants, COVID-19 Special Initiative (PEG 231377-1902992001), and the SSHRC's Insight Grant 231415-190299-2001.

Contributors RP and SY contributed to the study design and conceptualisation. AA and SM provided technical support. BOA performed the data analysis. MCM provided technical support and helped with the data analysis. All authors read and amended drafts of the paper and critically reviewed the manuscript for its intellectual content. SY had final responsibility to submit and he is the guarantor of this study. All authors approved the final version.

Funding This work was supported by the Social Sciences and Humanities Research Council (SSHRC) of Canada's Partnership Engage Grant \# 231377-190299.

\section{Competing interests None}

\section{Patient consent for publication Not required.}

Ethics approval and consent to participate Ethics approval was obtained from the Office of Research Ethics and Integrity of the University of Ottawa (S-0620-5911). The survey was open only to residents of Canada over the age of 18 . Respondents had to give an informed consent after reading the script. Sensitive questions could be skipped by the participants.

Provenance and peer review Not commissioned; externally peer reviewed.

Data availability statement The datasets generated during and/or analysed during the current study are available from the research team on reasonable request.

Open access This is an open access article distributed in accordance with the Creative Commons Attribution Non Commercial (CC BY-NC 4.0) license, which permits others to distribute, remix, adapt, build upon this work non-commercially, and license their derivative works on different terms, provided the original work is properly cited, appropriate credit is given, any changes made indicated, and the use is non-commercial. See: http://creativecommons.org/licenses/by-nc/4.0/.

\section{ORCID iDs}

Bright Opoku Ahinkorah http://orcid.org/0000-0001-7415-895X

Stephanie Maltais http://orcid.org/0000-0003-3752-0280

Sanni Yaya http://orcid.org/0000-0002-4876-6043

\section{REFERENCES}

1 Marchand-Senécal X, Kozak R, Mubareka S, et al. Diagnosis and management of first case of COVID-19 in Canada: lessons applied from SARS-CoV-1. Clin Infect Dis 2020;71:2207-10.

2 Chen L-P, Zhang Q, Yi GY, et al. Model-Based forecasting for Canadian COVID-19 data. PLoS One 2021;16:e0244536.

3 Detsky AS, Bogoch II. COVID-19 in Canada: experience and response. Jama 2020.

4 Worldometer. Coronavirus update published 2021, 2021. Available: https://www.worldometers.info/coronavirus/\#countries [Accessed June 24].

5 Bonilla-Aldana DK, Quintero-Rada K, Montoya-Posada JP, et al. SARS-CoV, MERS-CoV and now the 2019-novel CoV: Have we investigated enough about coronaviruses? - A bibliometric analysis. Travel Med Infect Dis 2020;33:101566. 
6 Ren L-L, Wang Y-M, Wu Z-Q, et al. Identification of a novel coronavirus causing severe pneumonia in human: a descriptive study. Chin Med J 2020;133:1015-24.

7 Guan W-jie, Ni Z-yi, Hu Y. Clinical characteristics of coronavirus disease 2019 in China. New England Journal of Medicine 2020;382:1708-20.

8 Huang C, Wang Y, Li X, et al. Clinical features of patients infected with 2019 novel coronavirus in Wuhan, China. The Lancet 2020;395:497-506

9 Chan JF-W, Yuan S, Kok K-H, et al. A familial cluster of pneumonia associated with the 2019 novel coronavirus indicating personto-person transmission: a study of a family cluster. Lancet 2020;395:514-23.

10 Brooks ZC, Das S. COVID-19 testing: impact of prevalence, sensitivity, and specificity on patient risk and cost. Am J Clin Pathol 2020;154:575-84.

11 Frank K, Arim R, Statistics Canada= Statistique Canada. Canadi'ns' Support for Random COVID-19 Testing 2020.

12 Vilches TN, Nourbakhsh S, Zhang K, et al. Multifaceted strategies for the control of COVID-19 outbreaks in long-term care facilities in Ontario, Canada. Prev Med 2021;148:106564.

13 Italy SE. And COVID-19: notes on the impact of the pandemic on the administration of justice. Access to Just. E. Eur 2020;148.

14 Lapointe-Shaw L, Rader B, Astley CM, et al. Web and phone-based COVID-19 syndromic surveillance in Canada: a cross-sectional study. PLoS One 2020;15:e0239886.

15 Canning D, Karra M, Dayalu R, et al. The association between age, COVID-19 symptoms, and social distancing behavior in the United States. medRxiv 2020. doi:10.1101/2020.04.19.20065219. [Epub ahead of print: 23 Apr 2020].
16 DC W, Jha P, Lam T. Determinants of self-reported symptoms and testing for COVID-19 in Canada using a nationally representative survey. medRxiv 2020.

17 Hilborne LH, Wagner Z, Cabreros I, et al. Linking statistics with testing policy to manage COVID-19 in the community. Am J Clin Pathol 2020;154:142-8.

18 Padula WV. Why only test symptomatic patients? consider random screening for covid-19 2020.

19 Thunström L, Ashworth M, Shogren JF, et al. Testing for COVID-19: willful ignorance or selfless behavior? Behav Public Policy 2021;5:135-52.

20 Akowuah JA, Agyei-Baffour P, Awunyo-Vitor D. Determinants of antenatal healthcare utilisation by pregnant women in third trimester in peri-urban Ghana. J Trop Med 2018;2018:1-8.

21 Joh E, Buchan SA, Daneman N. Factors associated with timely test seeking, test turnaround and public reporting of COVID-19: a retrospective analysis in Ontario, Canada. medRxiv 2021.

22 Thompson AE, Anisimowicz Y, Miedema B, et al. The influence of gender and other patient characteristics on health care-seeking behaviour: a QUALICOPC study. BMC Fam Pract 2016;17:1-7.

23 Dryhurst S, Schneider CR, Kerr J, et al. Risk perceptions of COVID-19 around the world. J Risk Res 2020;23:994-1006.

24 Mueller AL, McNamara MS, Sinclair DA. Why does COVID-19 disproportionately affect older people? Aging 2020;12:9959-81.

25 Shahid Z, Kalayanamitra R, McClafferty B, et al. COVID-19 and older adults: what we know. J Am Geriatr Soc 2020;68:926-9.

26 Garner R, Tanuseputro P, Manuel DG, et al. Transitions to longterm and residential care among older Canadians. Health Rep 2018;29:13-23.

27 Alami H, Lehoux P, Fleet R, et al. How can health systems better prepare for the next pandemic? lessons learned from the management of COVID-19 in Quebec (Canada). Front Public Health 2021;9:696. 